
\title{
25 Research Soure \\ Impact of the COVID-19 pandemic on attitudes towards the lifting of confinement through the Algerians people
}

\section{Azzeddine Madani ( $\sim$ azzeddine.madani@univ-dbkm.dz )}

University of Khemis Miliana

\section{Saad Eddine Boutebal}

University of Khemis Miliana

\section{Research Article}

Keywords: COVID-19; lifting of confinement; social attitudes; develop transport; develop public health sector.

Posted Date: July 17th, 2020

DOl: https://doi.org/10.21203/rs.3.rs-41206/v1

License: (c) (1) This work is licensed under a Creative Commons Attribution 4.0 International License. Read Full License 


\section{Abstract}

The aim of this study was to investigate the impact of the COVID-19 pandemic on the attitudes towards the lifting of confinement.

Methods: The data were collected using a questionnaire applied to 344 people in different regions of Algeria from April 21, 2020, for two weeks afterward, in order to determine the attitudes of the Algerian people towards the post-coronavirus COVID -19 phase.

Results: The results of this study indicate that $94.2 \%$ of respondents insist on lifting the confinement to apply gradually and partially. Accordingly, there is a significant impact of gender and age on social attitudes towards the post-coronavirus phase. Similarly, the results highlighted the existence of a positive level of attitude towards the post-coronavirus phase COVID-19 in the need to digitize education, digitize social transactions, and develop sustainable transport and the public health sector.

Results: People living in confinement indicate that it is necessary to prepare for the post-coronavirus period, in particular through the vital sectors linked to daily life.

\section{Introduction}

The coronavirus pandemic COVID-19 has changed the people's way of life in many countries around the world. So the World Health Organization (WHO) declared on January 26, 2020, the high risk of the epidemic in China and other countries [1]. In this direction, the organization recommended taking all necessary measures to prevent the spread of the epidemic on their territory. WHO reported that 3,175,207 people were infected and 224,172 people died because of the virus worldwide on May 1, 2020 [2]. In other words, the severity of the disease linked to the ability of the virus to spread and the difficulties in identifying those affected to manage them and avoid contamination [3]. Thus, this epidemic will have a short and long-term impact on societies, health systems, workplaces and people [4]. In effect, people carrying the virus can contaminate others with droplets respiratory and direct contact [1]. For this reason, the Chinese government decided to put in confinement an estimated of 50 million people and the total closure imposed on Wuhan on January 23, 2020, to ensure the social distancing for preventing people [5]. In addition, movement and displacement in contaminated regions were avoided when the epidemic started, and it was limited to only one area [6]. These measures obtained the expected results, and China was able to control the spread of the virus in this region for 2 months [7]. For this purpose, the Chinese government has improved public awareness of the prevention strategies undertaken by providing daily information and putting a stress management strategy through the intervention of health specialists on the internet [8].

Since most of the negative effects come from the imposition of a restriction of liberty, voluntary confinement is associated with less distress and long-term complication, this is why information is essential and people in confinement must understand the situation [9]. So that the influenza epidemic of 1918 showed that social distancing is very important to control an epidemic [10]. This confirms that 
confinement should remain a priority for the moment in the countries affected to fight against this epidemic, since the cost of short-term confinement will be lesser than the long-term cost of nonconfinement [11]. This is shown by the reacting way to epidemic and applying containment in many countries, including Europeans, has shown the lack of preparation of several countries and the slow nature of the decision-making processes [12]. According to [13] the countries affected by the epidemic take on average around three weeks to interact with the event. Thus, among other things, the procedure to be followed to get out of the confinement period arouses the interest of officials in many countries, so as this requires the implementation of preventive measures.

In effect, Algeria, like other countries in the world, was affected by the COVID-19 pandemic, and recorded 4,154 people infected by the coronavirus and 453 deaths as of May 1, 2020 [14]. Total confinement has been applied, since March 23, 2020, in the region of Blida which was very affected by the virus at the beginning of the epidemic and which facilitated the spread of the virus, as these statistics were before the extending of partial confinement for limited periods of time, from 7 p.m. to 7 a.m. and then extended from 3 p.m. to 7 a.m. to other regions of the country with provisions aimed at closing establishments in higher education sector and other sectors, with the demobilization of $50 \%$ of workers, and all these arrangements have been made when the number of people infected has increased rapidly, so the containment and mitigation strategies are based on the nature of the virus and how it spreads [15]. Algeria's peoples have lived since March 23, 2020, i.e. more than 40 days, in total or partial confinement in certain regions. The COVID-19 pandemic has caused significant impacts on the Algerian daily life and the functioning of the country's economy. Like what happened in China as industrial production fell by around $13.5 \%$, and retail sales fell by $21 \%$ till some sectors almost collapsed [16], this is what forced officials in many countries of the world think about returning to normal life and bringing people out of containment. For this purpose some countries have announced dates for breaking out of confinement without being able to apply them due to the increasing number of those infected. In Algeria, the dates to get out of confinement have been postponed each time, so this extension of confinement imposed by the risk of an increase in people with COVID-19 delayed the will of the authorities to return to normal life and boost the economy of the country. The population started following the events and the evolution of the pandemic, and this has caused psychological impacts which revealed questions linked to the lifting the confinement of the coronavirus epidemic in Algeria. It is shown by the attitudes and opinions of citizens towards the post-coronavirus phase.

Often the authorities are unbalanced when thinking about the social behavioral of individuals within daily life interaction with the coronavirus pandemic, especially in terms of the organization of behaviors and social preventive measures. It remains the only way to deal with the coronavirus currently, and the situation is made worse by the pressures of the difficulty of social and economic life and its complications in the various vital sectors of the country, hence scientific research is made to try to analyze this dilemma and perspectives for the benefit of society.

Currently, there are no studies in Algeria on social attitudes towards lifting the confinement and the post coronavirus phase COVID-19. Consequently, our study was launched on April 21, 2020, across the 
Algerian territory, and it aims at discovering the attitudes towards lifting the confinement and postcoronavirus in this period of confinement in Algeria, as the conception of a questionnaire allows knowing the attitudes towards this post-coronavirus phase. It is also a question of identifying the main attitudes associated with socio- demographic variables.

This study could help the authorities to better understand the attitudes of the population surveyed towards the actions to be taken in the context of lifting the confinement and the post-coronavirus phase, in order to better plan them. It is represented by confinement rules during the coronavirus in this study which were implemented by the Algerian state from March 23, 2020, to deal with the epidemic of coronavirus. The attitude towards the post-coronavirus phase signified the representations and the social points of view of citizens towards the demands of social interactions in daily life after lifting the confinement. This variable is measured and quantified through a questionnaire based on attitudes towards the post-coronavirus phase and includes the dimensions associated with daily life, namely the digitization of education, the digitization of social transactions, the soft mobility and the development of public health.

The present study represents a qualitative addition to the horizons and requirements of home confinement due to coronavirus through the ideas and opinions of citizens which are directly linked to living reality. Therefore, it is legitimate to think about the stage of reflection and planning to organize the process of home lift confinement in a rational way to avoid the spread of the coronavirus. The present study is limited by its research subject which deals with the attitudes of the population towards the postcoronavirus phase during confinement in Algeria, by a sample made up of 344 respondents and by the duration of the study in two weeks from April 21, 2020.

\section{Materials And Methods}

In this study we investigated the attitudes of Algerian citizens towards the post-coronavirus phase during confinement, with issues linked to daily life such as: education, daily transactions, transportation and health. We adopted a cross-sectional survey to determine attitudes towards the post-coronavirus phase during the confinement in Algeria, by using an online questionnaire which was widely disseminated with the help of university students. Our sampling strategy is based on the snowball method, which allows us to overcome the obstacles linked to confinement on one side and the need to study a problem which threatens our society on the other side, therefore this sampling has helped obtain a total of 344 respondents living during the confinement of the coronavirus epidemic in Algeria. The study sample consists of $62.5 \%$ men and $37.5 \%$ women. Among these participants are (31.7\%) aged 21 to $30,(37.8 \%)$ aged 31 to $40,(23.3 \%)$ aged 41 to 50 and (7.3\%) aged 51 to 60 .

\subsection{Tools (online questionnaire)}

The current questionnaire was constructed from a review of the theoretical literature on the variables and was designed online to facilitate its rapid dissemination and receive immediate answers during the period of home confinement. 
The attitude towards the post-coronavirus phase questionnaire in Algeria is divided into the following four dimensions:

- Digitization of teaching (10 items).

- Digitization of the social transaction (12 items).

- Soft mobility (9 items).

- Development of public health (15 items).

The questionnaire was designed on the standards of the three responses option scale, as we show in the following:

\begin{tabular}{lll} 
Not necessary & Only necessary in crisis & Necessary \\
\hline 1 & 2 & 3
\end{tabular}

The levels of attitudes towards the post-coronavirus phase are divided according to the dimensions appearing on the questionnaire, as shown below:

\begin{tabular}{|c|c|c|c|c|c|}
\hline \multicolumn{3}{|c|}{ Digitization of education } & \multicolumn{3}{|c|}{$\begin{array}{l}\text { Digitization of social transactions and } \\
\text { volunteering }\end{array}$} \\
\hline $10-15$ & $15-25$ & $25-30$ & $12-18$ & $18-30$ & $30-36$ \\
\hline Negative & Low & Positive & Negative & Low & Positive \\
\hline No need & Need & Strong necessity & No need & Need & Strong necessity \\
\hline \multicolumn{3}{|c|}{ Soft mobility } & \multicolumn{3}{|c|}{ Public health development } \\
\hline $9-13,5$ & $13,5-22,5$ & $22,5-27$ & $15-22,5$ & $22,5-37,5$ & $37,5-45$ \\
\hline Negative & Low & Positive & Negative & Low & Positive \\
\hline No need & Need & Strong necessity & No need & Need & Strong necessity \\
\hline
\end{tabular}

\subsection{Reliability and validity of the questionnaire}

The important conditions when designing a questionnaire are to ensure reliability and validity in order to trust the stability of its results, and that the latter really express the content to be measured. For this purpose, the Alpha-Cronbach reliability coefficient was calculated and the results were as shown below: 


\begin{tabular}{lc}
\multicolumn{1}{c}{ The dimension } & Alpha-Cronbach coefficient \\
\hline Digitization of education (10 items). &, 603 \\
\hline Digitization of the social transaction (12 items). &, 612 \\
\hline Soft mobility (9 items). &, 778 \\
\hline Public health development (15 items). &, 739
\end{tabular}

It is observed from these results that high values of Alpha-Cronbach coefficient are obtained in all dimensions, which confirms the reliability of the questionnaire. Among other things, the internal validity of the questionnaire was confirmed by calculating the correlation between the items and the total score of each dimension, so the correlations are all positive and statistically significant between $(0.305$ and $0.578)$ and significant $(P<0.05$ and $P<0.01)$. This increases confidence in the questionnaire results.

\section{2-3. Statistical analysis}

The data were processed using software SPSS 22 (SPSS Inc, Chicago, II, USA) in view of descriptive statistics (frequency, percentage, mean and standard deviation). The t-test was used to compare the mean scores of participants' attitudes with constant values to determine their level. Also, the chi-square test was used to assess the association between the different gender and age groups. The data obtained were evaluated in a confidence interval (95\% - 99\%).

\section{Results}

\subsection{Descriptive statistics for study variables}

Table 1 shows that the responders consists of 344 individuals ( $62.5 \%$ men and $37.5 \%$ women) and they are internet users, who live during the confinement of the coronavirus epidemic COVID-19 in Algeria. For the age variable we find $(37.8 \%)$ of the respondents are aged between 31 to 40 years (31.7\%) are between 21 to 30 years (23.3\%) are between 41 to 50 years and (7.3\%) are between 51 to 60 year old.

Furthermore, Table 1 indicates that (94.2\%) of the respondents confirms and insists on the need for the gradual and partial lifting the confinement in post-coronavirus phase COVID-19. On the other, we note that $(5.8 \%)$ of the respondents think that there is no obstacle to the overall lifting of home confinement.

Table 1 Descriptive statistics of socio-demographic variables and attitude towards lifting the confinement during the post-coronavirus phase COVID19 in Algeria 2020 


\begin{tabular}{|c|c|}
\hline Variables & $\mathrm{n} \quad \%$ \\
\hline \multicolumn{2}{|l|}{ Genre } \\
\hline Male & 21562,5 \\
\hline Femelles & 12937,5 \\
\hline \multicolumn{2}{|l|}{ Age } \\
\hline$(21-30)$ & 10931,7 \\
\hline$(31-40)$ & 13037,8 \\
\hline$(41-50)$ & 8023,3 \\
\hline$(51-60)$ & 257,3 \\
\hline \multicolumn{2}{|l|}{ Lifting the confinement } \\
\hline Global lift confinement & 205,8 \\
\hline Progressive lift confinement & 32494,2 \\
\hline \multicolumn{2}{|l|}{ Digitization of education } \\
\hline Necessary & 23367,7 \\
\hline Only necessary in crisis & 9928,8 \\
\hline Not necessary & 123,5 \\
\hline \multicolumn{2}{|c|}{ Digitization of social transactions and volunteering } \\
\hline Necessary & 22264,5 \\
\hline Only necessary in crisis & 8524,7 \\
\hline Not necessary & 3710,8 \\
\hline \multicolumn{2}{|l|}{ Soft mobility } \\
\hline Necessary & 25473,8 \\
\hline Only necessary in crisis & 5516,0 \\
\hline Not necessary & 3510,2 \\
\hline \multicolumn{2}{|l|}{ Public health development } \\
\hline Necessary & 26476,7 \\
\hline Only necessary in crisis & 4814,0 \\
\hline Not necessary & 329,3 \\
\hline
\end{tabular}

The results which highlight the social attitudes towards the post-coronavirus phase COVID-19, show that $(76.7 \%)$ of the respondents insist on the importance of developing the health sector in response to the significant deficiencies observed in the phase of the coronavirus epidemic COVID-19 in Algeria. It is also noticed that $(73.8 \%)$ indicated the need to develop soft transport that preserves the environment and human health. In addition, $(67.7 \%)$ of the respondents stressed the importance and the need to digitize education in the post- Coronavirus phase and (64.5\%) confirmed not only the necessity of promoting and digitizing general and commercial transactions in daily life, but also digitized voluntary activity and develop it. To move towards the partial lifting of containment, it is necessary to carefully study the infected areas and allow the regions to resume a normal life and daily activity with preventive measures. It is not useful to rely too much on a broad and effective social awareness when considering the lifting of partial containment. First, we must prepare the conditions for the gradual exit from containment; this does not mean that the control measures against COVID- 19 must be lifted, since if all these measures are lifted at once, a second epidemic peak will be expected. It is necessary to put in place means of health protection in the streets, sterilizers and disinfectants, install public toilets according to the highest sanitary standards, provide mechanisms of isolation and social separation between citizens in the various places. 
According to the results presented in table 2 there are significant differences between the average scores of social attitudes towards the post-coronavirus phase during confinement in Algeria and the theoretical values indicating the highest positive level and the strong need of attitude. First, the results show that there is a strong positive attitude towards the need for the digitization of education ( $M=26.4826 \mathrm{SD}=$ 3.71503) towards the post-coronavirus phase COVID-19, because of the great school interruption and the closure of all educational establishments, which has led to the need to think of an effective alternative to ensure a certain level of the educational process. In addition, with the great difficulties in using virtual teaching and educational platforms.

This result indicates the need to use educational technology on the one hand, and that this technology helps considerably to cope with the spread of various epidemics, including the coronavirus COVID-19. Therefore, it is important to pay more attention to developing the skills of teachers and students to use distance learning technology through various applications and online platforms.

Table $2 \mathrm{~T}$ test for the single sample of attitude levels towards the post-coronavirus phase COVID-19 during confinement in Algeria 2020 ( $\mathrm{n}=344$ )

\begin{tabular}{|c|c|c|c|c|c|c|}
\hline Variables & Test value & M & SD & $\mathrm{t} \quad \mathrm{P}$ & P-Value & $\begin{array}{c}\text { Level } \\
\text { Attitude }\end{array}$ \\
\hline Digitization of education & 25 & 26,482 & 3,71503 & 7,402 & 0,001 & $\begin{array}{c}\text { Positive } \\
\text { Strong necessity }\end{array}$ \\
\hline Digitization of social transactions and volunteering & 30 & 31,116 & 5,61530 & 3,687 & 0,001 & $\begin{array}{c}\text { Positive } \\
\text { Strong necessity }\end{array}$ \\
\hline Soft mobility & 22,5 & 23,439 & 5,29390 & 3,290 & 0,001 & $\begin{array}{c}\text { Positive } \\
\text { Strong necessity }\end{array}$ \\
\hline Public health development & 37,5 & 40,155 & 8,47500 & 5,821 & 0,001 & $\begin{array}{c}\text { Positive } \\
\text { Strong necessity }\end{array}$ \\
\hline
\end{tabular}

Table 2 also indicates that there is an attitude with great necessity regarding the digitization of social transactions and volunteering $(M=31.1163 \mathrm{SD}=5.61530)$ in the post-Coronavirus phase (COVID-19). This is to avoid the negative effects of home confinement when the pandemic spreads and reduces direct interactions between people in order to minimize the spread of infection. It is achieved by the digitization of public administrations, commercial transactions, and by encouraging voluntary associations to these forms of digitization, without forgetting the need to think about developing telework mechanisms according to the specificity of each profession.

The results show the existence of positive attitudes in favor of the need to develop soft and sustainable transport in social life $(M=23.4390 S D=5.29390)$ to become an available alternative if the pandemics spread again, and this through the development of the use of bicycles and walking, as well as the promotion of public transport according to preventive standards against the transmission of infections. Furthermore, these results indicate a positive attitude with a considerable need to develop the health sector $(M=40.1599 S D=8.47500)$. Indeed, the health sector has a direct relationship to the spread of epidemics, and any weakness in this sector negatively affects the health care of citizens. Therefore, it is necessary to develop health education, scientific research and health and therapeutic innovations, the 
creation of quality hospitals and the support of health associations. It is also necessary to develop mechanisms of monitoring food for citizen's health in all its aspects.

3.3 Impact of socio-demographic variables (gender, age) on the attitudes towards the post coronavirus phase COVID-19 in Algeria

Table 3 Association of socio-demographic variables (gender, age) and participants' attitudes towards the post-coronavirus phase COVID-19 in Algeria $2020(n=344)$.

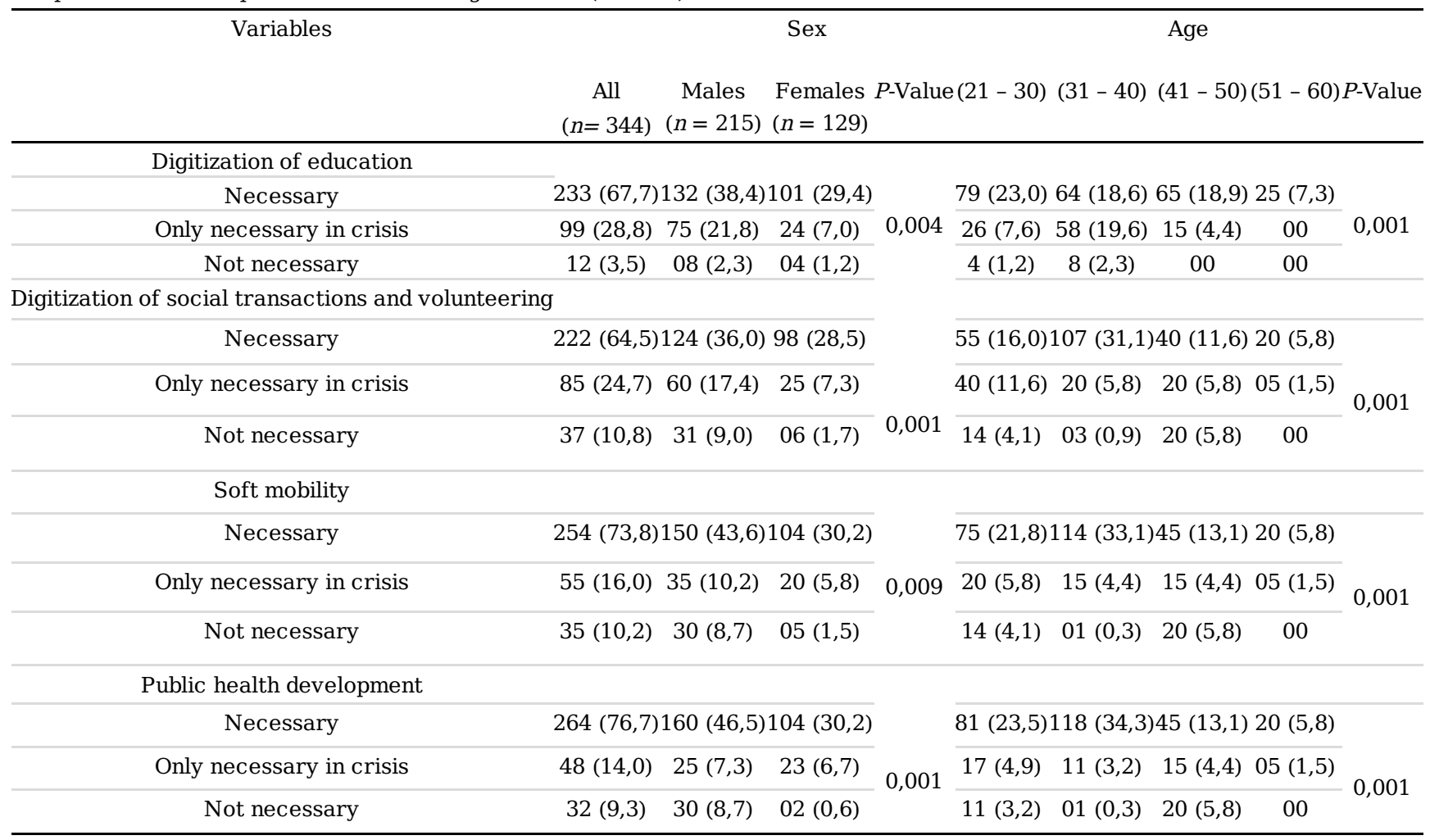

According to Table 3 , it is found in the first place, that $46.5 \%$ of male respondents and $30.2 \%$ of women who indicated the need to develop public health. There is a significant association between the two gender groups and this dimension $(P=0.001)$.

$43.6 \%$ of males and $30.2 \%$ of females respondents said that there is a need to develop soft mobility, There is a significant association between the two gender groups and the attitude towards soft mobility $(P=0.009)$. In addition, $38.4 \%$ of male participants and $29.4 \%$ of female participants said that there is a need to digitize education, there is a significant association between the two gender groups and the attitude towards digitization of education $(P=0.004)$.

$36 \%$ of male participants and $28.5 \%$ of women indicated that it is necessary to digitize social transactions and support for volunteering, there is a significant association between the two gender groups and this dimension $(P=0.001)$. The gender variable is associated with positive attitudes regarding the digitization of education and social transactions, even also for the development of soft mobility and the public health sector. Certainly, participating men are more likely to manifest these 
attitudes. In addition, $67.7 \%$ of the participants declared that it was necessary to digitize education, hence there is a significant association between the different age groups and the attitude towards the digitization of education ( $P=0.001)$. In addition, $64.5 \%$ of participants said that it was necessary to digitize social transactions and support for volunteering, there is thus a significant association between the different age groups and this dimension $(P=0.001)$.

$73.8 \%$ of the participants confirmed the need to develop soft mobility, there is a significant association between the different age groups and the attitude towards soft mobility $(P=0.001)$. It is also found that $76.7 \%$ of participants said there is a need to develop public health. There is a significant association between the different age groups and this dimension $(P=0.001)$. Indeed, age groups are associated with positive attitudes regarding the digitization of education and social transactions, even also for the development of soft mobility and the public health sector. Participants who are 40 years or younger $(\leqslant 40)$ are more likely to exhibit these attitudes.

\section{Discussion}

The study indicates that $94.2 \%$ of respondents insist on lift confinement to apply gradually and partially, because they are aware of direct risk in global lift confinement, especially after a period of rapid increase in fear and anxiety in people due to this new disease [17]. In addition, there is an urgent need to implement the prevention measures in daily life. Knowing that some people with COVID-19 do not have a fever or symptoms, so this complicates the diagnosis [18]. At the same time it is still difficult to fight against COVID-19 of unknown origin and mysterious biological characteristics and to control an epidemic of this virus with very high transmission and a long incubation period [19]. While the respondents are also aware that the preventive measures to be installed in workplaces and shops must be strengthened even more to ensure a safe distance, especially since the number of people with COVID-19 doubles in 6.4 days [20] and that one day, in the near future, broader containment measures may be required to prevent peoples [21]. Thus, lift confinement requires the implementation of emergency prevention measures and the identification, by all countries, of the best actions to return safely to work in different places including in schools. Returning to activity require disinfection measures and well-planned actions to provide more protection [22].

In effect, the lifting of confinement must be gradual and stepwise, so that the state can provide extensive means of prevention against the coronavirus, in addition to control the behavior of individuals and groups in a way that contributes to support preventive measures, especially in public places, markets and institutions that people visit frequently, Little by little, people get used to certain behaviors to integrate into their daily interaction with a view to coexistence with the coronavirus until its elimination. One cannot expect the risks of a complete and total lifting of the confinement at home because of its great risk of resuscitating the control of coronavirus in a difficult way.

The finding revealed that the level of attitude towards the post-coronavirus phase COVID-19 among the respondents was a strong positive towards the need for the digitization of education and this is linked to 
the great interruption in education and the closure of establishments in Algeria. Knowing also that on March 18, 2020, officials from 107 countries had closed national schools following the COVID-19, thus depriving 862 million children and young people of the continuity of their education [23]. This has prompted the search for alternatives through distance education. This positive attitude result obliges to pay more attention to the developments of this type of distance education through the development of the skills of teachers and students for the mastery of distance education technology and online educational platforms.

This study requires special attention to what have shown, the digitization of teaching and the education system is, therefore, an absolute necessity required by the requirements of modern technological life on the one hand, and in the case of various emergency crises on the other hand, such as the coronavirus pandemic. This allows us to reflect on perfecting the skills of computerization among teachers and students, and again, the implementation of virtual education platforms that must be developed in this sense

The results of this study indicated the existence of a positive attitude towards the need of digitizing social transactions and voluntary actions, and this is to avoid the negative effects of direct contacts between people, since the behavior of individuals will be important in controlling the spread of epidemic COVID-19 [24]. The digitization of administrations, commercial transactions and voluntary activities as well as the development of telework by the establishment of the classification of trades to be exercised remotely and regulatory texts to properly frame this form of activity, are actions to take in the postcoronavirus period COVID-19. Knowing that workers in many professions are at high risk of being infected in pandemics in addition to the lasting societal effects of coronavirus which are still impossible to estimate [4]. So, we indicated the need to digitize social transactions in everyday life, especially with regard to stores and shopping centers that work to meet the daily needs of citizens, so that the use of electronic payment cards has become more than a necessity and even the public administrations that people visit frequently because of their interests, they are also required to strive to digitize their sectors, especially in an epidemic like the one we are experiencing today.

The human aspect should not be neglected so that it can be digitized by people belonging to needy groups who need multi-shade support at the time of the coronavirus epidemic, in order to facilitate the access to them and provide the required support in a timely manner.

The results of the present study also suggest the existence of a positive attitude in favor of the development of soft and sustainable transport in society which preserves the environment, and human health with prevention measures. Thus, the encouragement of the use of the bicycle is necessary by the installation of temporary cycle paths; many countries are currently developing arrangements to install temporary cycle paths. Faced with the dangers of the coronavirus, it has become urgent to think of using safer means of transport, such as the bicycle, with the need to propose its own paths and to encourage citizens to use them as part of healthy behavior in the social environmental. Also the public transport 
must be organized in a way that allows social separation between individuals according to the instructions for combating the coronavirus.

The current study concluded that there are positive attitude for the development of the health sector in the post-coronavirus phase, to avoid the deficiencies and saturation recorded in hospitals during the pandemic, which caused not only the risk of death from infection but also unbearable psychological pressure [25] It is also necessary to develop health education, scientific research in the field of health and the construction of quality hospitals with prevention standards can also protecting medical personnel, who also need support on the mental health plan during epidemics [26] since the hospital environment plays an important role in the activity of medical personnel. The weakness of the health establishments in our country and the major challenges which the health sector is confronted require to rethink the global and qualitative reform of hospitals, health structures and various medical technological installations, of course without forgetting the importance good sponsorship of human resources in the health sector and associations of sociable society linked to the sector.

Among other things, the impact of gender and age on social attitudes towards the post-coronavirus phase in the population surveyed during confinement in Algeria, shows that the gender variable is associated with positive attitudes, male respondents are more likely to exhibit these attitudes. And that age groups are associated with positive attitudes, Respondents whose age is less than or equal to 40 years $(\leqslant 40)$ are more likely to manifest these attitudes. In our society, men are more in touch with the interactions of daily life than women, because most of the requirements of the home are provided by men, and therefore their attitudes towards the requirements of the lifting of containment are more important and clear, and the same goes for groups under 40 years about the current situation due to the coronavirus and its consequences after home lift confinement.

This study has several limits related to the time-sensibility of the pandemic COVID-19 for this purpose we adopted snowball sampling, knowing that it was not based on random selection, and the study population did not reflect the reality of the general population. The future perspectives of this study can also be integrated into research questions on health attitudes, quality of life, the roles of social media at the pandemic, and the associations with demographic variables.

\section{Conclusion}

The Algerian population surveyed in this study looks at the post-coronavirus phase more seriously to avoid falling back into the future in the impacts experienced during confinement. Through the study, we discover the importance of the opinions and attitudes of citizens with regard to the post-coronavirus period, especially through the vital sectors linked to daily life, in the process of helping the authorities in the effective organization of the post-coronavirus phase.

The results of this study lead us to try to explore and anticipate the prospects of lifting confinement at home because of the coronavirus in Algeria, and the different challenges that will be imposed on the State and on society to try to coexist with the epidemic to its end. So, it takes a solid will to prepare for 
similar crises in the future, especially in terms of digitization and development of sectors linked to the daily life of Algerians citizen.

\section{Declarations}

Ethics approval and consent to participate: Not applicable

Availability of data and material: All data generated or analyzed during this study are included in this published article.

Consent for publication: Not applicable

Competing interests: The authors declare that they have no competing interests.

Funding: This study received no funding.

Authors' contributions: Boutebal \& Madani designed the study; Boutebal \& Madani collected and analyzed the data; Madani \& Boutebal both wrote, revised and reviewed the manuscript. The author(s) read and approved the final manuscript.

Statement on Participant Consent: Participants were invited to participate in the online survey, they had the choice of answering or not. The introduction to the survey informed that this is part of academic research. All responses were anonymous.

\section{References}

1. Fan, C., Liu, L., Guo, W., Yang, A., Ye, C., Jilili, M., ... \& Wang, Y(2020).Prediction of epidemic spread of the 2019 novel coronavirus driven by Spring Festival transportation in China: a population-based study. International journal of environmental research and public health, 17(5):1679. https://doi.org/10.3390/ijerph17051679

2. WHO, «novel-coronavirus-2019/situation-reports,» 3 Mai 2020. [En ligne]. Available: https://www.int/emergencies/diseases/novel-coronavirus-2019/situation-reports. [Accès le 4 Mai 2020].

3. Munster, V. J., Koopmans, M., van Doremalen, N., van Riel, D., \& de Wit, E. (2020).A novel coronavirus emerging in China-key questions for impact assessment. New England Journal of Medicine, 382(8): 692-694. https://doi.org/10.1056/NEJMp2000929

4. Burdorf, A., Porru, F., \& Rugulies, R.(2020).The COVID-19 (Coronavirus) pandemic: consequences for occupational health. Scandinavian Journal of Work, Environment \& Health., 46 (3) : 229-230 https://doi.org/10.5271/sjweh.3893 
5. Wang, C., Pan, R., Wan, X., Tan, Y., Xu, L., Ho, C. S., \& Ho, R. C (2020) .Immediate psychological responses and associated factors during the initial stage of the 2019 coronavirus disease (COVID19) epidemic among the general population in china. International Journal of Environmental Research and Public Health, 17(5): 1729, 2020. https://doi.org/10.3390/ijerph17051729

6. Kraemer, M. U., Yang, C. H., Gutierrez, B., Wu, C. H., Klein, B., Pigott, D. M., ... \& Brownstein, J. S (2020). The effect of human mobility and control measures on the COVID-19 epidemic in China. Science, 368(6490): 493-497. https://doi.org/10.1126/science.abb4218

7. Verity, R., Okell, L. C., Dorigatti, I., Winskill, P., Whittaker, C., Imai, N., ... \& Dighe, A (2020) .Estimates of the severity of coronavirus disease 2019: a model-based analysis. The Lancet Infectious Diseases, 20(6): 669- 677 https://doi.org/10.1016/S1473-3099(20)30243-7

8. Bao, Y., Sun, Y., Meng, S., Shi, J., \& Lu, L (2020). 2019-nCoV epidemic: address mental health care to empower society. The Lancet, 395(10224): e37-e38. https://doi.org/10.1016/S0140-6736(20)303093

9. Brooks, S. K., Webster, R. K., Smith, L. E., Woodland, L., Wessely, S., Greenberg, N., \& Rubin, G. J (2020). The psychological impact of quarantine and how to reduce it: rapid review of the evidence. The Lancet, 395 (10227): 912-920. https://doi.org/10.1016/S0140-6736(20)30460-8

10. Smith, R (2007) .Social measures may control pandemic flu better than drugs and vaccines. BMJ, 334:1341. https://doi.org/10.1136/bmj.39255.606713.DB

11. Wilder-Smith, A., Chiew, C. J., \& Lee, V. J. (2020). Can we contain the COVID-19 outbreak with the same measures as for SARS?. The Lancet Infectious Diseases, 20 (5): e102-e107 https://doi.org/10.1016/S1473- 3099(20)30129-8

12. Bailly (2020). COVID-19 Chroniques d'un géographe de la santé. 30 Mars 2020. [En ligne]. Available: https://codevirusshs.wixsite.com/website. [Accès le 14 Avril 2020].

13. Tellis, G. J., Sood, A., \& Sood, N (2020). How Long Should Social Distancing Last? Predicting Time to Moderation, Control, and Containment of COVID-19. (March 28, 2020),» 28 March 2020. [En ligne]. Available: https://papers.ssrn.com/sol3/papers.cfm?abstract_id=3562996. https://dx.doi.org/10.2139/ssrn.3562996

14. MSPRH (2020).Point de situation. 3 Mai 2020. [En ligne]. Available: http://www.sante.gov.dz/coronavirus/coronavirus-2019/82-documentation/640-point-de-situationde-l- epidemie-de-coronavirus-covid-19-au-03-mai-2020.html. [Accès le 3 Mai 2020].

15. Fauci, A. S., Lane, H. C., \& Redfield, R. R (2020). Covid-19-navigating the uncharted. The New England Journal of Medicine. https://doi.org/10.1056/NEJMe2002387 
16. McKee, M., \& Stuckler, D (2020).If the world fails to protect the economy, COVID-19 will damage health not just now but also in the future.,» Nature Medicine:1-3. https://doi.org/10.1038/s41591020-0863-y

17. Sood S (2020). Psychological effects of the Coronavirus disease-2019 pandemic. RHiME [Internet]. 2020Apr.1 [cited 2020Jul.11]; 70:23-6. Available from:

https://www.rhime.in/ojs/index.php/rhime/article/view/264

18. Guan, W. J., Ni, Z. Y., Hu, Y., Liang, W. H., Ou, C. Q., He, J. X., ... \& Du, B (2020). Clinical characteristics of coronavirus disease 2019 in China. New England Journal of Medicine, 382 (18):1708-1720. https://doi.org/10.1056/NEJMoa2002032

19. Xie, M., \& Chen, Q (2020). Insight into 2019 novel coronavirus - an updated intrim review and lessons from SARS-CoV and MERS-CoV. International Journal of Infectious Diseases, 94:119-124 https://doi.org/10.1016/j.ijid.2020.03.071

20. Wu, J. T., Leung, K., \& Leung, G. M (2020). Nowcasting and forecasting the potential domestic and international spread of the 2019-nCoV outbreak originating in Wuhan, China: a modelling study. The Lancet, 395(10225):689-697. https://doi.org/10.1016/S0140-6736(20)30260-9

21. Z, «What further should be done to control COVID-19 outbreaks in addition to cases isolation and contact tracing measures?.,» BMC medicine, 18(1): 1-3. https://doi.org/10.1186/s12916-020-01551-8

22. Dalton, C.B., Corbett, S.J. and Katelaris, A.L (2020), COVID -19: implementing sustainable low cost physical distancing and enhanced hygiene. Med. J. Aust., 212(10): 443-446.e1. https://doi.org/10.5694/mja2.50602

23. Viner, R. M., Russell, S. J., Croker, H., Packer, J., Ward, J., Stansfield, C., ... \& Booy, R (2020).School closure and management practices during coronavirus outbreaks including COVID-19: a rapid systematic review. The Lancet Child \& Adolescent Health, 4(5):397-404. https://doi.org/10.1016/S2352-4642(20)30095-X

24. Anderson, R. M., Heesterbeek, H., Klinkenberg, D., \& Hollingsworth, T. D (2020) .How will countrybased mitigation measures influence the course of the COVID-19 epidemic?. The Lancet, 395(10228):931-934. https://doi.org/10.1016/S0140-6736(20)30567-5

25. Cao, W., Fang, Z., Hou, G., Han, M., Xu, X., Dong, J., \& Zheng, J (2020). The psychological impact of the COVID-19 epidemic on college students in China. Psychiatry research. Psychiatry research, 287:112934. https://doi.org/10.1016/j.psychres.2020.112934

26. Xiang, Y. T., Yang, Y., Li, W., Zhang, L., Zhang, Q., Cheung, T., \& Ng, C. H (2020). Timely mental health care for the 2019 novel coronavirus outbreak is urgently needed. The Lancet Psychiatry, 7(3):228229. https://doi.org/10.1016/S2215-0366(20)30046-8 